\title{
Maxillary Sinus Floor Augmentation: a Review of Selected Treatment Modalities
}

\author{
Thomas Starch-Jensen', Janek Dalsgaard Jensen ${ }^{1}$ \\ ${ }^{1}$ Department of Oral and Maxillofacial Surgery, Aalborg University Hospital, Aalborg, Denmark.
}

\author{
Corresponding Author: \\ Thomas Starch-Jensen \\ Department of Oral and Maxillofacial Surgery \\ Aalborg University Hospital \\ 18-22 Hobrovej, DK-9000 Aalborg \\ Denmark \\ Phone: +459766 2798 \\ Fax: +4597662825 \\ E-mail: thomas.jensen@rn.dk
}

\begin{abstract}
Objectives: The objective of the present study is to present the current best evidence for enhancement of the vertical alveolar bone height and oral rehabilitation of the atrophic posterior maxilla with dental implants and propose some evidence-based treatment guidelines.

Material and Methods: A comprehensive review of the English literature including MEDLINE (PubMed), Embase and Cochrane Library search was conducted assessing the final implant treatment outcome after oral rehabilitation of the atrophic posterior maxilla with dental implants. No year of publication restriction was applied. The clinical, radiological and histomorphometric outcome as well as complications are presented after maxillary sinus floor augmentation applying the lateral window technique with a graft material, maxillary sinus membrane elevation without a graft material and osteotomemediated sinus floor elevation with or without the use of a graft material.

Results: High implant survival rate and new bone formation was reported with the three treatment modalities. Perforation of the Schneiderian membrane was the most common complication, but the final implant treatment outcome was not influenced by a Schneiderian membrane perforation.

Conclusions: The different surgical techniques for enhancement of the vertical alveolar bone height in the posterior part of the maxilla revealed high implant survival with a low incidence of complications. However, the indication for the various surgical techniques is not strictly equivalent and the treatment choice should be based on a careful evaluation of the individual case. Moreover, further high evidence-based and well reported long-term studies are needed before one treatment modality might be considered superior to another.
\end{abstract}

Keywords: alveolar ridge augmentation; dental implants; oral surgical procedures; review; sinus floor augmentation.

\author{
Accepted for publication: 30 September 2017 \\ To cite this article: \\ Starch-Jensen T, Jensen JD. \\ Maxillary Sinus Floor Augmentation: a Review of Selected Treatment Modalities \\ J Oral Maxillofac Res 2017;8(3):e3 \\ URL: http://www.ejomr.org/JOMR/archives/2017/3/e3/v8n3e3.pdf \\ doi: $10.5037 /$ jomr.2017.8303
}




\section{INTRODUCTION}

Periodontal disease and dental caries are the main causes of tooth loss and the incidence of edentulous patients varies worldwide between $7 \%$ and $69 \%$ [1] Complete or partial tooth loss is often associated with nutritional deficiencies, oral pain, and poor psychosocial functioning. During the last 40 years, osseointegrated dental implants have become one of the most used biomaterial to replace missing or lost teeth and the treatment has been characterised by a highly successful outcome of complete, partial or single edentulism [2-5]. Oral rehabilitation with implant-supported prosthesis have shown improved masticatory function and oral specific health-related quality of life compared to removable dentures $[\underline{6}, \underline{7}]$. However, placement of implants in the posterior part of the maxilla is frequently compromised or impossible due to atrophy of the alveolar process, poor bone quality and maxillary sinus pneumatization. Therefore, vertical alveolar ridge augmentation is often necessary before or in conjunction with installation of implants. Various surgical approaches comprising elevation of the Schneiderian membrane have been proposed in order to achieve the necessary vertical height of the alveolar process for the installation of implants with a sufficient length including maxillary sinus floor augmentation with the lateral window technique, osteotome-mediated sinus floor elevation and sinus membrane elevation without the use of a graft material [ $\underline{8-10]}$. However, the treatment of choice for the most appropriate surgical intervention for oral rehabilitation of the atrophic posterior maxillary ridge with implants is influenced by the vertical height of the residual alveolar bone, local intrasinus anatomy and the number of teeth to be replaced [10].

Different types of biomaterials have been used for maxillary sinus floor augmentation including autograft, allograft, xenograft, alloplast, and growth factors, and the selection of the ideal graft material has been a subject of controversy over the years. Autogenous bone graft is considered the golden standard in augmentation procedures due to its osteoinductive, osteogenic and osteoconductive characteristics [11]. However, the use of autogenous bone grafts is associated with risk of donor site morbidity and unpredictable graft resorption [1219]. Therefore, various bone substitutes of biologic or synthetic origin are used increasingly to simplify the surgical procedure by diminishing the need for bone harvesting. The treatment outcome after enhancement of the vertical alveolar bone height in the posterior part of the maxilla with the different treatment modalities is well-documented and has been reported in numerous systematic reviews and meta-analysis [20-34]. Although, the conclusions are often based on short-term non-comparative studies. Therefore, the objective of this comprehensive review is to present the current evidence for enhancement of the vertical alveolar bone height in the posterior part of the maxilla and propose some evidencebased treatment guidelines for oral rehabilitation of the atrophic posterior maxilla with dental implants.

\section{SURGICAL METHODS FOR ENHANCEMENT OF THE ALVEOLAR BONE HEIGHT IN THE POSTERIOR MAXILLA}

Maxillary sinus floor augmentation applying the lateral window technique with a grafting material and simultaneous or delayed implant installation

Maxillary sinus floor augmentation using the lateral window technique was originally developed by Tatum [35] in the mid-seventies and afterwards described by Boyne and James in 1980 [36]. This surgical intervention is still the most frequently used method to enhance the vertical alveolar bone height of the posterior part of the maxilla before or in conjunction with installation of implants, and the treatment outcome has been reported in several systematic reviews and meta-analysis [20-25].

\section{Surgical technique}

Maxillary sinus floor augmentation applying the lateral window technique is usually performed under local anaesthesia and sedation. The maxillary sinus is exposed through the oral mucosa in the region of the anterior and lateral maxillary sinus wall. A midcrestal incision is made with posterior and anterior vertical releasing incisions. A mucoperiosteal flap with a trapezoid base is reflected exposing the lateral wall of the maxillary sinus. A trapdoor osteotomy is performed on the lateral wall of the maxillary sinus with burrs and a high-speed handpiece or piezoelectric surgery advoiding laceration of the Schneiderian membrane (Figure 1A). The trapdoor is infractured and the Schneiderian membrane is carefully dissected and elevated from the maxillary sinus floor as well as the lateral and medial sinus wall and displaced dorsocranially with blunt dissector to create a compartment for placement of the graft material (Figure 1B). Implants are inserted 

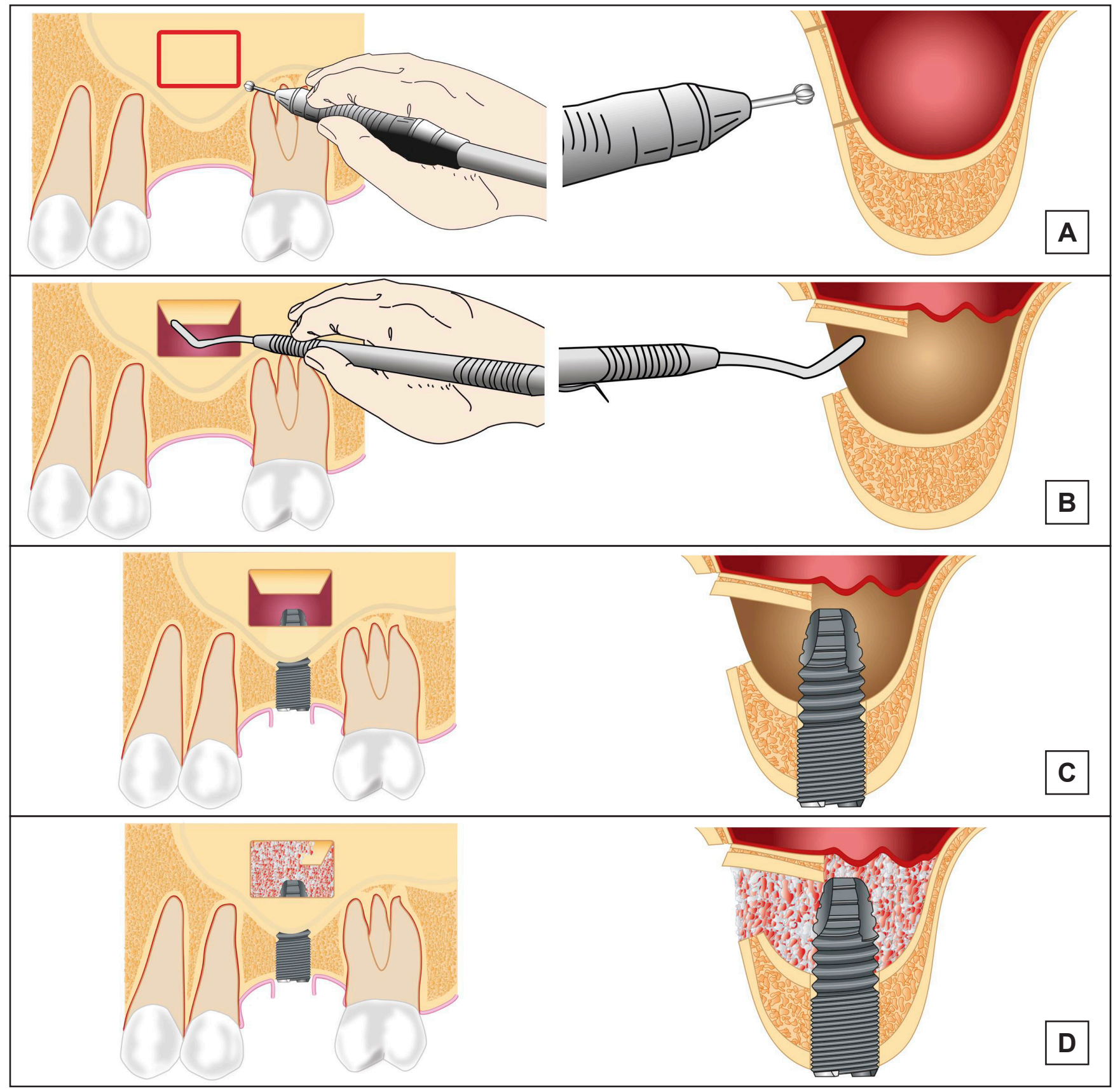

Figure 1. Maxillary sinus floor augmentation applying the lateral window technique with a grafting material. A = a trapdoor osteotomy is performed on the lateral wall of the maxillary sinus. $\mathrm{B}=$ the trapdoor is infractured and the Schneiderian membrane is carefully dissected and elevated from the maxillary sinus floor to create a compartment for placement of the graft material. $\mathrm{C}=$ the implant is inserted simultaneously with the augmentation procedure. $\mathrm{D}=$ the graft material is densely packed around the exposed implant surface in the created compartment.

simultaneously with the augmentation procedure, if the height of the residual alveolar bone provides sufficient primary implant stability. An implant bed is successively prepared with burrs before the implant are inserted in the residual alveolar bone with the implant tip exposed in the created compartment in the maxillary sinus (Figure 1C). The graft material is densely packed around the exposed implant surface to facilitate de novo bone formation (Figure 1D). The lateral window to the maxillary sinus is usually covered by a resorbable collagen membrane to prevent ingrowth of fibrous tissue before the mucoperiosteum is readapted and sutured. If primary implant stability is compromised, then the implants are inserted 4 to 12 months after the augmentation procedure. Final prosthetic solution is performed three to six months after implant installation.

\section{Clinical outcome}

Recent systematic reviews and meta-analysis have assessed the implant survival after maxillary sinus 
floor augmentation with various types of graft materials disclosing an overall implant survival rate well-beyond 90\% [20-25]. The implant survival rate was equivalent regardless of the used graft material and time of implant placement $[\underline{24}, \underline{25}]$. Moreover, a newly published systematic review and metaanalysis assessing the long-term implant treatment outcome concluded that maxillary sinus floor augmentation with autogenous bone graft, mixture of autogenous bone graft and bone substitutes or bone substitutes alone seem to be a highly predictable and successful surgical procedure to enhance the vertical alveolar bone height of the posterior part of the maxilla before or in conjunction with implant placement with a high implant survival rate [24].

\section{Radiological and histomorphometric outcome}

Recent published systematic reviews assessing histomorphometric variables after maxillary sinus floor augmentation concluded that autogenous bone graft resulted in the highest amount of newly formed bone in comparison to various bone substitutes, though allografts, alloplastic materials and xenografts seemed to be a good alternative to autogenous bone graft $[\underline{23}, \underline{37}]$. Moreover, a meta-analysis assessing the total bone volume after maxillary sinus floor augmentation based on histomorphometric analysis demonstrated a significantly higher proportion of mineralized bone during the early healing phase when autogenous bone was used as graft as compared with various bone substitutes used alone or in combination with autogenous bone graft [38]. However, a healing period of more than 9 months revealed no statistically significant differences between the different treatment modalities [37]. A newly published systematic review and meta-analysis evaluated the effect of a barrier membrane over the lateral window demonstrating similar amount of bone formation with or without a barrier membrane [39]. Moreover, the type of grafting material and healing time did not influence the histomorphometric outcome [39]. The effect of autogenous platelet concentrates on the clinical and histomorphometric outcome has previously been evaluated in a systematic review disclosing no evidenced beneficial effect of platelet concentrates due to large heterogeneity among the included studies [40]. The bone-to-implant contact and the volumetric stability of the graft material after maxillary sinus floor with autogenous bone graft alone or in combination with different ratios of deproteinized bovine bone mineral has been evaluated in an experimental minipigs model $[\underline{18}, \underline{41}]$.
It was concluded that the bone-to-implant contact was significantly higher when autogenous bone graft or deproteinized bovine bone mineral mixed with autogenous bone graft in different ratios were used as compared to deproteinized bovine bone mineral alone, after 12 weeks [41]. In addition, fluorochrome labelling indicated that the early bone to implant contact formation adjacent to the implant surface was more advanced with autogenous bone graft compared to deproteinized bovine bone mineral [41]. Computed tomography scans obtained preoperatively, immediately after surgery, and after 12 weeks showed a significant volumetric reduction of autogenous bone grafts from the iliac crest and the mandible [18]. Increased graft preservation occurred after the addition of deproteinized bovine bone mineral and the volumetric reduction was significantly influenced by the ratio of deproteinized bovine bone mineral and autogenous bone graft [18]. Volumetric dimensional changes of the graft material after maxillary sinus floor augmentation has previously been assessed in a systematic review concluding that some loss of the augmentation volume always occurs, but bone substitutes or composite grafts display less volume reduction compared to autogenous bone graft [19].

\section{Complications}

Perforation of the Schneiderian membrane is the most common operative complication during maxillary sinus floor augmentation [42-45]. Presence of sinus septa and a residual bone height less than $3.5 \mathrm{~mm}$ increases the risk for a sinus membrane perforation [46]. However, perforation of the Schneiderian membrane seems not to influence the final treatment outcome [42-45], but a higher prevalence for sinusitis is reported in cases of membrane perforation [46]. Other complications include bleeding, migration of dental implants into the maxillary sinus, postoperative infection, sinusitis, exposure of the graft, graft loss, oedema, seroma formation, benign paroxysmal positional vertigo and exposure of the collagen membrane. Smokers generally exhibited greater chances for complications and a newly published systematic review concluded that smoking seems to be associated with increased risk of wound dehiscence and infection after maxillary sinus floor augmentation $[\underline{46}, \underline{47}]$. However, complications related to maxillary sinus floor augmentation applying the lateral window technique with a grafting material are generally low and not severe, as documented in systematic reviews $[\underline{20}, \underline{24}]$. 


\section{Conclusion and clinical recommendations}

Maxillary sinus floor augmentation applying the lateral window technique with a grafting material is a safe and predictable surgical procedure with low morbidity for oral rehabilitation of the severely atrophic posterior maxilla with dental implants. This surgical intervention is recommended when the height of the residual alveolar bone is less than $6 \mathrm{~mm}$. Dental implants are inserted simultaneously with the augmentation procedure, if the height of the residual alveolar bone provides sufficient primary implant stability. If not, then the implants are inserted 4 to 12 months after the augmentation procedure, depending of the used graft material.

Maxillary sinus membrane elevation applying the lateral window technique without a graft material and simultaneous implant installation

Maxillary sinus membrane elevation using the lateral window technique without a graft material and simultaneous installation of implants was introduced by Lundgren et al. in 2004 [48]. This surgical intervention requires sufficient vertical height of the residual alveolar bone in the posterior part of the maxilla to achieve primary implant stability, since immediate implant installation is necessary to preserve and support the elevated Schneiderian membrane, allowing coagulum formation round the exposed implant surface in the sinus cavity. The treatment outcome has been reported in various systematic reviews and meta-analysis involving predominantly short-term non-comparative studies $[\underline{26}, \underline{27}, \underline{29}, \underline{30}, \underline{34}]$, but long-term studies are scarce.

\section{Surgical technique}

The formation of the lateral window, elevation of the Schneiderian membrane and implant installation is similar to the surgical technique described above for maxillary sinus floor augmentation with a grafting material and simultaneous implant installation, although the implant bed is usually prepared with an undersized drilling protocol and the lateral cortical bony window is often dissected free and removed from the underlying Schneiderian membrane (Figure 2A). A blood coagulum is formed around the exposed implant tip in the secluded compartment between the elevated Schneiderian membrane and the original floor of the maxillary sinus (Figure 2B). The lateral window to the maxillary sinus is covered by a resorbable collagen membrane or the dissected lateral cortical bony window. The mucoperiosteum is readapted and sutured
(Figure 2C). Final prosthetic solution is usually performed three to six months after maxillary sinus membrane elevation and implant installation, when de novo bone is formed around the implant (Figure 2D).

\section{Clinical outcome}

Recent systematic reviews and meta-analysis have assessed the implant survival after maxillary sinus membrane elevation using the lateral window technique without a graft material and simultaneous installation of implants disclosing an implant survival rate beyond $90 \%[26,27,29,30,34]$. However, longterm studies are scarce. A 5-year implant survival rate of $100 \%$ has been reported after maxillary sinus membrane elevation without a graft material and simultaneous installation of 80 implants in 44 patients [49]. Moreover, an implant survival of $99 \%$ has been described in a 1 to 6-year follow-up study involving 189 implants inserted in 84 patients [50]. However, only 14 implants inserted in 6 patients were followed for 6 years [무] .

\section{Radiological and histomorphometric outcome}

Assessment of intra-sinus new bone formation and bone density after maxillary sinus membrane elevation using the lateral window technique without a graft material has been compared with maxillary sinus floor augmentation applying the lateral window technique with autogenous bone graft or allogenic mineralized bone graft $[51,52]$. The average vertical alveolar bone gain after 6 months was $7.9 \mathrm{~mm}$ without a graft material and $8.3 \mathrm{~mm}$ when an autogenous bone graft was used [51]. There was no significant difference in the vertical alveolar bone gain between the two treatment modalities at any time-points [51]. Radiographic assessment showed that the bone density increased significantly during the observation period, but the bone density was significantly higher in sinuses augmented with a blood clot compared to an allogenic mineralized bone graft after 6 months [52]. A non-comparative study assessing maxillary sinus membrane elevation with the lateral window technique without a graft material demonstrated an intra-sinus vertical alveolar bone gain of $7.4 \mathrm{~mm}$ after 5 years, with no significant changes in the gained bone height between 2 and 5 years [52]. Moreover, the gain in intra-sinus vertical alveolar bone height was increased significantly for implants protruding longer into the sinus cavity compared to implants with only a minor part of the implant tip exposed $[\underline{52}, \underline{53}]$. Histologic evaluation of biopsies retrieved after maxillary sinus membrane elevation with the lateral 

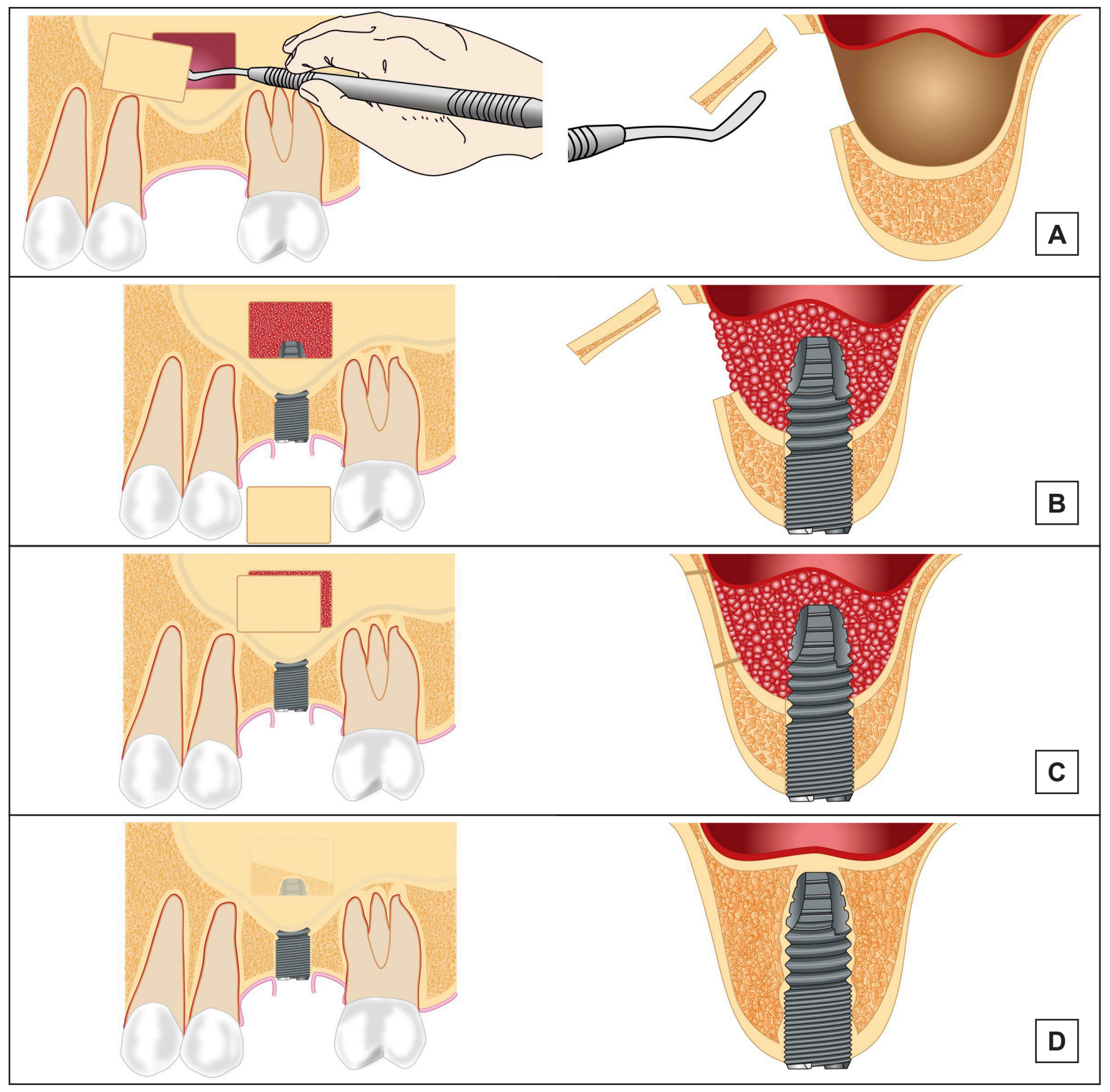

Figure 2. Maxillary sinus membrane elevation applying the lateral window technique without a graft material and simultaneous implant installation. $\mathrm{A}=$ the lateral cortical bony window is dissected free and removed from the underlying Schneiderian membrane, which is carefully elevated from the maxillary sinus floor to create a compartment for placement of the graft material. B $=$ a blood coagulum is formed around the exposed implant tip in the secluded compartment between the elevated Schneiderian membrane and the original floor of the maxillary sinus. $\mathrm{C}$ = the window to the maxillary sinus is covered by the dissected lateral cortical bony window. $\mathrm{D}=$ new bone formation around the implant tip in the previous created compartment.

window technique without a graft material revealed new bone formation and a mean vital bone volume varying between $39 \%$ and $60 \%$, after 6 months [54-56].

\section{Complications}

Perforation of the sinus membrane was the most frequent intraoperative complication, although very rare $[26,27,29,30]$. A higher risk of sinus membrane perforationhas been reported, when the lateral cortical bony window was dissected free and removed from the underlying Schneiderian membrane [29]. However, the treatment outcome seems not to be influenced by a sinus membrane perforation, although implant loss has been reported in a case with a perforation of the sinus membrane $[29,50]$. Other complications reported included postoperative infection, exposure of the covering membrane, swelling, mild postoperative oedema, pain, loosening of 
healing abutments, and nose bleeding [29].

\section{Conclusion and clinical recommendations}

Maxillary sinus membrane elevation applying the lateral window technique without a graft material and simultaneous implant installation seems to be a safe and predictable surgical procedure with few complications and a high short-term implant survival rate. However, no consensus has yet been reached on the amount of bone formation and predictability for installation of numerous implants in the posterior part of the maxilla with this surgical intervention. Moreover, long-term clinical and radiographic studies assessing the final implant treatment outcome are scarce. Thus, further long-term comparative studies are needed before final conclusion can be provided about this surgical intervention for oral rehabilitation of the atrophic posterior maxilla with dental implants. It is our opinion that maxillary sinus membrane elevation using the lateral window technique without a graft material and simultaneous implant installation should solely be recommended for single implant installation, when a limited amount of bone regeneration is needed.

Osteotome-mediated sinus floor elevation and simultaneous installation of implants with or without the use of a graft material

The osteotome-mediated transcrestal sinus lift approach was first proposed by Tatum in 1986 [35]. In 1994, Summers [57] described a modification of this technique using a set of tapered osteotomes with increasing diameters intended to increase the density of the soft bone and create an up-fracture of the maxillary sinus floor. The Schneiderian membrane and the maxillary sinus floor is elevated from a transcrestal approach using osteotomes creating a compartment for graft placement and/ or blood clot formation, without the preparation of a lateral window. Implants are inserted immediately to support the elevated floor of the maxillary sinus with the Schneiderian membrane. Osteotome-mediated sinus floor elevation is most suitable for installation of a single implant but can be used for multiple implants. The treatment outcome has been reported in reviews, systematic reviews and meta-analysis comprising predominantly short-term studies [3133,58-61]. Osteotome-mediated sinus floor elevation with simultaneous installation of implants with or without the use of a grafting material are considered less invasive and time-consuming than maxillary sinus floor augmentation applying the lateral window technique.

\section{Surgical technique}

Osteotome-mediated sinus floor elevation and simultaneous installation of implants with or without the use of a graft material is performed under local anaesthesia and sedation. An intraoral midcrestal incision is made with or without a vertical releasing incision. Mucoperiosteum is reflected along the residual alveolar ridge and the implant position is marked on the alveolar crest with a small round bur. The implant bed is prepared with a series of osteotomes with increasing diameter or in combination with burrs to a depth approximately 1 to $2 \mathrm{~mm}$ away from the maxillary sinus floor boundary (Figure 3A). An up-fracture of the maxillary sinus floor is made with a mallet under light tapping and the Schneiderian membrane with the maxillary sinus floor is carefully elevated using an osteotome or a blunt instrument (Figure 3B). The integrity of the membrane is controlled with Valsalva maneuver, before grafting material may be added to the lifted area underneath the elevated Schneiderian membrane with the original maxillary sinus floor. The implant is inserted in the residual alveolar bone with the implant tip exposed in the lifted area (Figure 3C). Mucoperiosteum is readapted and sutured. Final prosthetic solution is performed three to six months after osteotome-mediated sinus floor elevation with simultaneously implant installation, when de novo bone is formed around the implant (Figure 3D).

\section{Clinical outcome}

Various systematic reviews and meta-analysis have assessed the implant survival after osteotomemediated sinus floor elevation and simultaneous installation of implants with or without the use of a graft material revealing an overall implant survival rate higher than $90 \%[31-33,58-61]$. However, longterm studies are scarce. A newly published systematic review and meta-analysis disclosed no statistically significant difference in short-term implant survival rate between osteotome-mediated sinus floor elevation and simultaneous installation of implants with or without the use of a graft material [61]. A 10-year implant survival rate of $100 \%$ has been reported after osteotome-mediated sinus floor elevation and simultaneous installation of 23 implants in 15 patients without the use of a graft material [62]. The implant survival rate after osteotome-mediated sinus floor elevation and simultaneous installation of implants is significantly higher when the residual vertical alveolar bone height is more than $5 \mathrm{~mm}$, as documented in a systematic review [32]. Moreover, installation 


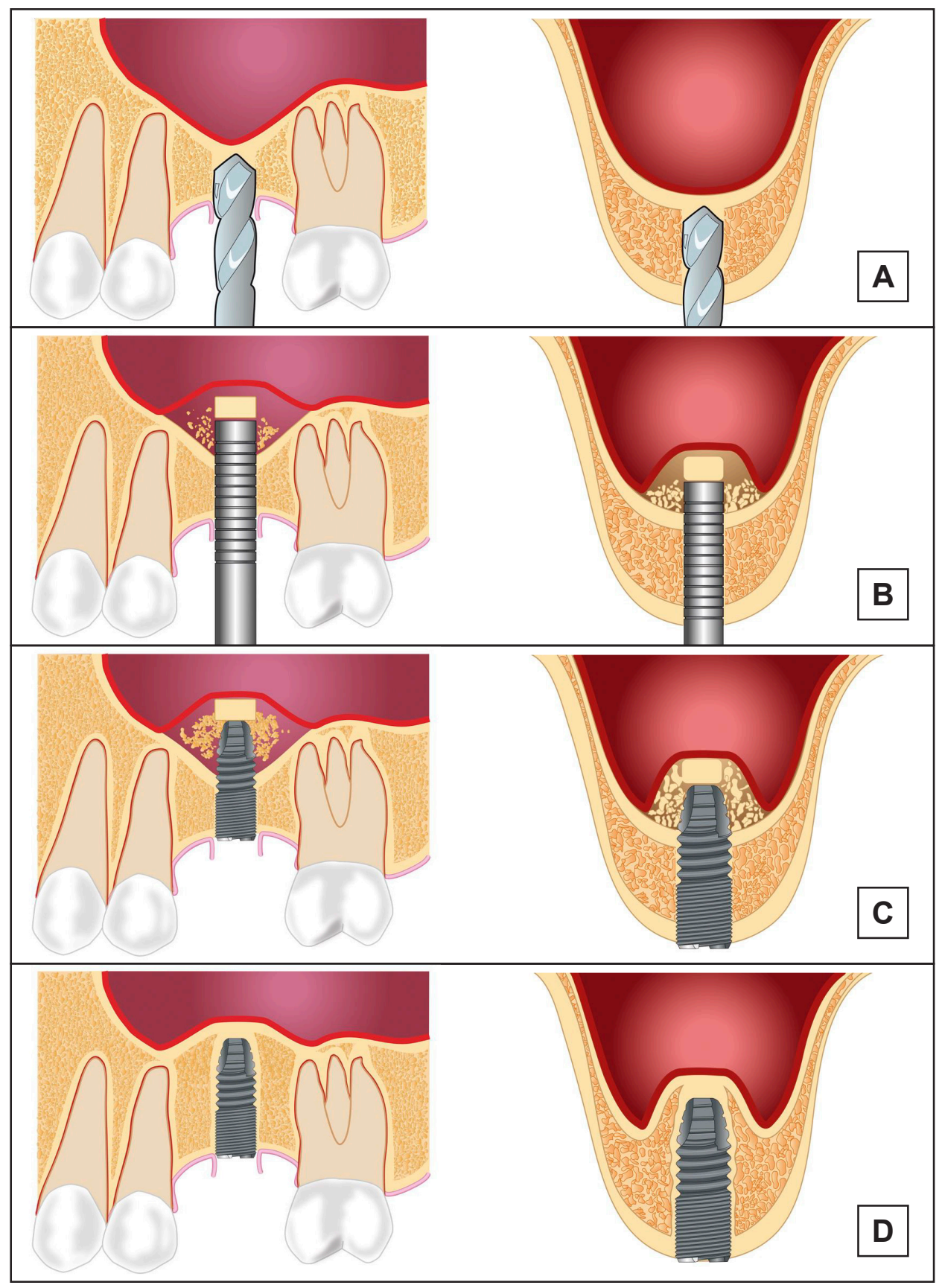

Figure 3. Osteotome-mediated sinus floor elevation and simultaneous installation of implants with or without the use of a graft material. $\mathrm{A}=$ the implant bed is prepared with a series of osteotomes with increasing diameter or in combination with burrs to a depth approximately 1-2 $\mathrm{mm}$ away from the maxillary sinus floor boundary. $\mathrm{B}=$ an up-fracture of the maxillary sinus floor is made with a mallet under light tapping and the Schneiderian membrane with the maxillary sinus floor is carefully elevated with the osteotome or a blunt instrument. $\mathrm{C}=$ the implant is inserted in the residual alveolar bone with the implant tip exposed in the lifted area. $\mathrm{D}=$ new bone formation around the implant tip in the previous created compartment.

of short implants $(\leq 6 \mathrm{~mm})$ in conjunction with osteotome-mediated sinus floor elevation significantly diminished the implant survival rate [툐.

\section{Radiological and histomorphometric outcome}

The 3-year radiographic assessment of intra-sinus new bone formation after osteotome-mediated sinus floor elevation and simultaneous installation of implants ranged from 3.17 to $5.1 \mathrm{~mm}$ with a graft material and from 1.7 to $4.1 \mathrm{~mm}$ without a graft material, as documented in a systematic review and metaanalysis [61]. Moreover, a prospective radiographic study assessing the intra-sinus vertical alveolar bone gain after osteotome-mediated sinus floor elevation and simultaneous installation of implants revealed significantly more bone gain with a grafting material compared to the use of no graft [62]. The 10-year radiographic intra-sinus new bone formation was $3 \mathrm{~mm}$ without the use of a graft material and bone 
formation was more pronounced during the first year and tends to increase for three years [63]. Consequently, osteotome-mediated sinus floor elevation with a graft material and simultaneous installation of implants seem to facilitate more vertical alveolar bone gain compared to the use of no graft material.

\section{Complications}

Perforation of the Schneiderian membrane is the most common operative complication after osteotomemediated sinus floor elevation and simultaneous installation of implants with or without the use of a graft material with a mean incidence of 3.8\% (range 0 to 21.4) [64]. An oblique maxillary sinus floor, sinus septa and root apices penetrating into the maxillary sinus increases the risk of Schneiderian membrane perforation. However, perforation of sinus membrane seems not to influence the implant survival rate [64]. Other complications include postoperative infection, disorientated after surgery, nose bleeding, blocked nose, hematomas, benign paroxysmal positional vertigo and postoperative bleeding [58].

\section{Conclusion and clinical recommendations}

Osteotome-mediated sinus membrane elevation is a predictable and reliable approach to oral rehabilitation of the atrophic posterior maxilla with a high implant survival rate. However, there is a paucity of long-term studies and installation of short implants $(\leq 6 \mathrm{~mm})$ significantly diminished the implant survival rate.
Hence, osteotome-mediated sinus membrane elevation is usually indicated when a residual vertical alveolar bone height of more than $6 \mathrm{~mm}$ is present. Autogenous bone graft or bone substitutes can be added, if more intra-sinus bone gain is needed for installation of implants with a desirable length.

\section{CONCLUSIONS}

Various surgical techniques have been proposed in order to achieve the necessary vertical alveolar bone height for the insertion of dental implants in the posterior part of the maxilla disclosing high implant survival rate with a low incidence of complications. However, the indication for the three above-mentioned surgical techniques is not strictly equivalent and the treatment choice should be based on a careful evaluation of the individual case. The residual vertical alveolar bone height and the ability to achieve primary implant stability is considered fundamental in deciding which augmentation technique should be used to obtain an adequate vertical bone height for installation of dental implants with a desirable length in the posterior part of the maxilla. When a residual vertical alveolar bone height of more than $5 \mathrm{~mm}$ is present, osteotome-mediated sinus floor elevation and simultaneous installation of implants with or without the use of a graft material is usually indicated. Otherwise, when the residual bone height is $5 \mathrm{~mm}$ or less, maxillary sinus floor augmentation using the lateral window technique with a grafting material lateral window approach is indicated (Figure 4).

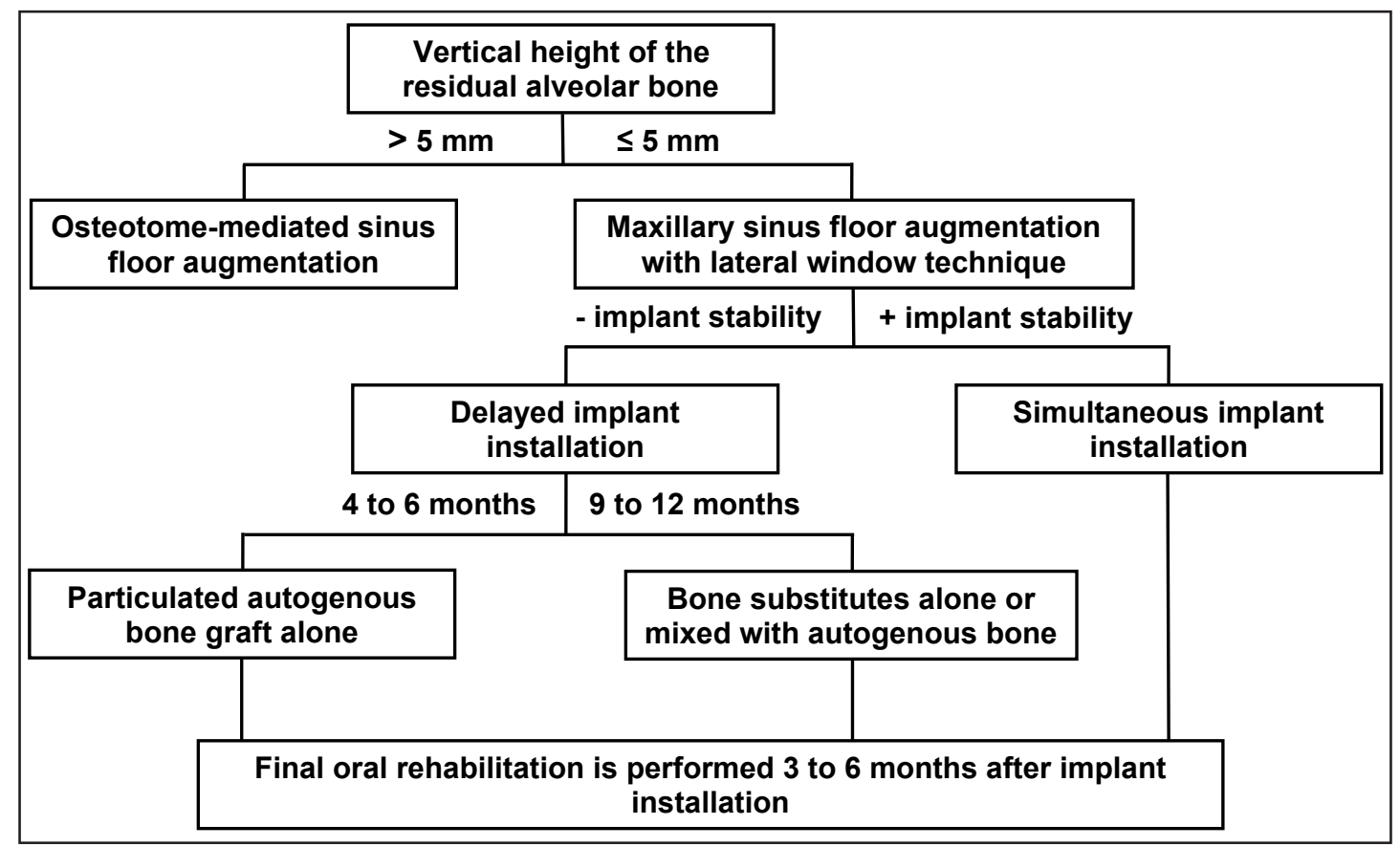

Figure 4. Treatment guidelines for enhancement of the vertical alveolar bone height and oral rehabilitation of the atrophic posterior maxilla with implants. 
Maxillary sinus membrane elevation using the lateral window technique without a graft material and simultaneous implant installation is solely suggested when a limited amount of bone regeneration is needed for installation of implants. However, further high evidence-based and well reported long-term studies are needed to clarify the specific indications for each treatment modality. Moreover, short dental implants or alternative treatment options should be considered for each individual patient.

\section{ACKNOWLEDGMENTS AND DISCLOSURE STATEMENTS}

The authors declare that there are no financial or other conflicts of interest related to this publication.

\section{REFERENCES}

1. Petersen PE, Bourgeois D, Bratthall D, Ogawa H. Oral health information systems--towards measuring progress in oral health promotion and disease prevention. Bull World Health Organ. 2005 Sep;83(9):686-93. [Medline: 16211160] [PMC free article: 2626332]

2. Berglundh T, Persson L, Klinge, BA. A systematic review of the incidence of biological and technical complications in implant dentistry reported in prospective longitudinal studies of at least 5 years. JClin Periodontol. 2002;29(suppl3):197-212, discussion 232-3. [Medline: 12787220] [doi: 10.1034/j.1600-051X.29.s3.12.x]

3. Pjetursson BE, Thoma D, Jung R, Zwahlen M, Zembic A. A systematic review of the survival and complication rates of implant-supported fixed dental prostheses (FDPs) after a mean observation period of at least 5 years. Clin Oral Implants Res. 2012 Oct;23(suppl6):22-38. [Medline: 23062125] [doi: 10.1111/j.1600-0501.2012.02546.x]

4. Jung RE, Zembic A, Pjetursson BE, Zwahlen M, Thoma DS. Systematic review of the survival rate and the incidence of biological, technical, and aesthetic complications of single crowns on implants reported in longitudinal studies with a mean follow-up of 5 years. Clin Oral Implants Res. 2012 Oct;23(suppl6):2-21. [Medline: 23062124] [doi: 10.1111/j.1600-0501.2012.02547.x]

5. Buser D, Sennerby L, De Bruyn H. Modern implant dentistry based on osseointegration: 50 years of progress, current trends and open questions. Periodontol 2000. 2017 Feb;73(1):7-21. [Medline: 28000280] [doi: 10.1111/prd.12185]

6. Emami E, Heydecke G, Rompré PH, de Grandmont P, Feine JS. Impact of implant support for mandibular dentures on satisfaction, oral and general health-related quality of life: a meta-analysis of randomized-controlled trials. Clin Oral Implants Res. 2009 Jun;20(6):533-44. [Medline: 19515032] [doi: 10.1111/j.1600-0501.2008.01693.x]

7. Boven GC, Raghoebar GM, Vissink A, Meijer HJ. Improving masticatory performance, bite force, nutritional state and patient's satisfaction with implant overdentures: a systematic review of the literature. J Oral Rehabil. 2015 Mar;42(3):22033. [Medline: 25307515] [doi: 10.1111/joor.12241]

8. Carreño Carreño J, Aguilar-Salvatierra A, Gómez-Moreno G, García Carreño EM, Menéndez López-Mateos ML, Perrotti V, Piattelli A, Calvo-Guirado JL, Menéndez-Núñez M. Update of Surgical Techniques for Maxillary Sinus Augmentation: A Systematic Literature Review. Implant Dent. 2016 Dec;25(6):839-844. [Medline: 27540841] [doi: 10.1097/ID.0000000000000467]

9. Danesh-Sani SA, Loomer PM, Wallace SS. A comprehensive clinical review of maxillary sinus floor elevation: anatomy, techniques, biomaterials and complications. Br J Oral Maxillofac Surg. 2016 Sep;54(7):724-30. [Medline: 27235382] [doi: 10.1016/j.bjoms.2016.05.008]

10. Lundgren S, Cricchio G, Hallman M, Jungner M, Rasmusson L, Sennerby L. Sinus floor elevation procedures to enable implant placement and integration: techniques, biological aspects and clinical outcomes. Periodontol 2000. 2017 Feb;73(1):103-20. [Medline: 28000271] [doi: 10.1111/prd.12165]

11. Burchardt H. The biology of bone graft repair. Clin Orthop Relat Res. 1983 Apr;174:28-42. [Medline: 6339139] [doi: 10.1097/00003086-198304000-00005]

12. Nkenke E, Stelzle F. Clinical outcomes of sinus floor augmentation for implant placement using autogenous bone or bone substitutes: a systematic review. Clin Oral Implants Res. 2009 Sep; 20(Suppl 4):124-33. [Medline: 19663959] [doi: 10.1111/j.1600-0501.2009.01776.x]

13. Johansson B, Grepe A, Wannfors K, Hirsch JM. A clinical study of changes in the volume of bone grafts in the atrophic maxilla. Dentomaxillofac Radiol. 2001 May;30(3):157-61. [Medline: 11420628] [doi: 10.1038/sj.dmfr.4600601]

14. Clavero J, Lundgren S. Ramus or chin grafts for maxillary sinus inlay and local onlay augmentation: comparison of donor site morbidity and complications. Clin Implant Dent Relat Res. 2003;5(3):154-60. [Medline: 14575631] [doi: $10.1111 / j .1708-8208.2003 . t b 00197 . x]$

15. Cricchio G, Lundgren S. Donor site morbidity in two different approaches to anterior iliac crest bone harvesting. Clin Implant Dent Relat Res. 2003;5(3):161-9. [Medline: 14575632] [doi: 10.1111/j.1708-8208.2003.tb00198.x] 
16. Wiltfang J, Schultze-Mosgau S, Nkenke E, Thorwarth M, Neukam FW, Schlegel KA. Onlay augmentation versus sinuslift procedure in the treatment of the severely resorbed maxilla: a 5-year comparative longitudinal study. Int J Oral Maxillofac Surg. 2005;34(8):885-9. [Medline: 15978775] [doi: 10.1016/j.ijom.2005.04.026]

17. Zizelmann C, Schoen R, Metzger MC, Schmelzeisen R, Schramm A, Dott B, Bormann KH, Gellrich NC. Bone formation after sinus augmentation with engineered bone. Clin Oral Implants Res. 2007 Feb;18(1):69-73. [Medline: 17224026] [doi: $10.1111 / j .1600-0501.2006 .01295 . x$ ]

18. Jensen T, Schou S, Svendsen PA, Forman JL, Gundersen HJ, Terheyden H, Holmstrup P. Volumetric changes of the graft after maxillary sinus floor augmentation with Bio-Oss and autogenous bone in different ratios. A radiographic study in minipigs. Clin Oral Implants Res. 2012 Aug;23(8):902-10. [Medline: 22044477] [doi: 10.1111/j.1600-0501.2011.02245.x]

19. Shanbhag S, Shanbhag V, Stavropoulos A. Volume changes of maxillary sinus augmentations over time: a systematic review. Int J Oral Maxillofac Implants. 2014 Jul-Aug;29(4):881-92. [Medline: 25032768] [doi: 10.11607/jomi.3472]

20. Jensen T, Schou S, Stavropoulos A, Terheyden H, Holmstrup P. Maxillary sinus floor augmentation with Bio-Oss or Bio-Oss mixed with autogenous bone as graft: a systematic review. Clin Oral Implants Res. 2012 Mar;23(3):263-73. [Medline: 21443592] [doi: 10.1111/j.1600-0501.2011.02168.x]

21. Esposito M, Felice P, Worthington HV. Interventions for replacing missing teeth: augmentation procedures of the maxillary sinus. Cochrane Database Syst Rev. 2014 May 13;(5):CD008397. [Medline: 24825543] [doi: 10.1002/14651858]

22. Aghaloo TL, Misch C, Lin GH, Iacono VJ, Wang HL. Bone Augmentation of the Edentulous Maxilla for Implant Placement: A Systematic Review. Int J Oral Maxillofac Implants. 2016;31 Suppl:19-30. [Medline: 27228250] [doi: $10.11607 /$ jomi.16suppl.g1]

23. Danesh-Sani SA, Engebretson SP, Janal MN. Histomorphometric results of different grafting materials and effect of healing time on bone maturation after sinus floor augmentation: a systematic review and meta-analysis. J Periodontal Res. 2017 Jun;52(3):301-12. [Medline: 27534916] [doi: 10.1111/jre.12402]

24. Starch-Jensen T, Aludden H, Hallman M, Dahlin C, Christensen AE, Mordenfeld A. A systematic review and metaanalysis of long-term studies (five or more years) assessing maxillary sinus floor augmentation. Int J Oral Maxillofac Surg. 2017 May 22. [Medline: 28545806] [doi: 10.1016/j.ijom.2017.05.001]

25. Ting M, Rice JG, Braid SM, Lee CYS, Suzuki JB. Maxillary Sinus Augmentation for Dental Implant Rehabilitation of the Edentulous Ridge: A Comprehensive Overview of Systematic Reviews. Implant Dent. 2017 Jun;26(3):438-64. [Medline: 28520572] [doi: 10.1097/ID.0000000000000606]

26. Duan DH, Fu JH, Qi W, Du Y, Pan J, Wang HL. Graft-Free Maxillary Sinus Floor Elevation: A Systematic Review and Meta-Analysis. J Periodontol. 2017 Jun;88(6):550-64. [Medline: 28168901] [doi: 10.1902/jop.2017.160665]

27. Silva LD, de Lima VN, Faverani LP, de Mendonça MR, Okamoto R, Pellizzer EP. Maxillary sinus lift surgery-with or without graft material? A systematic review. Int J Oral Maxillofac Surg. 2016 Dec;45(12):1570-76. [Medline: 27765427] [doi: 10.1016/j.ijom.2016.09.023]

28. Nasr S, Slot DE, Bahaa S, Dörfer CE, Fawzy El-Sayed KM. Dental implants combined with sinus augmentation: What is the merit of bone grafting? A systematic review. J Craniomaxillofac Surg. 2016 Oct;44(10):1607-17. [Medline: 27622972] [doi: 10.1016/i.jems.2016.06.022]

29. Starch-Jensen T, Schou S. Maxillary Sinus Membrane Elevation With Simultaneous Installation of Implants Without the Use of a Graft Material: A Systematic Review. Implant Dent. 2017 Aug;26(4):621-33. [Medline: 28639983] [doi: 10.1097/ID.0000000000000617]

30. Moraschini V, Uzeda MG, Sartoretto SC, Calasans-Maia MD. Maxillary sinus floor elevation with simultaneous implant placement without grafting materials: a systematic review and meta-analysis. Int J Oral Maxillofac Surg. 2017 May;46(5):636-47. [Medline: 28254402] [doi: 10.1016/j.ijom.2017.01.021]

31. Călin C, Petre A, Drafta S. Osteotome-mediated sinus floor elevation: a systematic review and meta-analysis. Int J Oral Maxillofac Implants. 2014 May-Jun;29(3):558-76. [Medline: 24818194] [doi: 10.11607/jomi.3206]

32. Del Fabbro M, Corbella S, Weinstein T, Ceresoli V, Taschieri S. Implant survival rates after osteotome-mediated maxillary sinus augmentation: a systematic review. Clin Implant Dent Relat Res. 2012 May;14 Suppl 1:e159-68. [Medline: 22082056] [doi: 10.1111/j.1708-8208.2011.00399.x]

33. Corbella S, Taschieri S, Del Fabbro M. Long-term outcomes for the treatment of atrophic posterior maxilla: a systematic review of literature. Clin Implant Dent Relat Res. 2015 Feb;17(1):120-32. [Medline: 23656352] [doi: 10.1111/cid.12077]

34. Pinchasov G, Juodzbalys G. Graft-free sinus augmentation procedure: a literature review. J Oral Maxillofac Res. 2014 Apr 1;5(1):e1. [Medline: 24800051] [doi: 10.5037/jomr.2014.5101]

35. Tatum H Jr. Maxillary and sinus implant reconstruction. Dent Clin North Am. 1986 Apr;30(2):207-29. [Medline:3516738]

36. Boyne PJ, James RA. Grafting of the maxillary sinus floor with autogenous marrow and bone. J Oral Surg. 1980 Aug;38(8):613-6. [Medline: 6993637]

37. Corbella S, Taschieri S, Weinstein R, Del Fabbro M. Histomorphometric outcomes after lateral sinus floor elevation procedure: a systematic review of the literature and meta-analysis. Clin Oral Implants Res. 2016 Sep;27(9):1106-22. [Medline: 26452326] [doi: 10.1111/clr.12702]

38. Handschel J, Simonowska M, Naujoks C, Depprich RA, Ommerborn MA, Meyer U, Kübler NR. A histomorphometric meta-analysis of sinus elevation with various grafting materials. Head Face Med. 2009 Jun 11;5:12. [Medline: 19519903] [doi: 10.1186/1746-160X-5-12] 
39. Suárez-López Del Amo F, Ortega-Oller I, Catena A, Monje A, Khoshkam V, Torrecillas-Martínez L, Wang HL, GalindoMoreno P. Effect of barrier membranes on the outcomes of maxillary sinus floor augmentation: a meta-analysis of histomorphometric outcomes. Int J Oral Maxillofac Implants. 2015 May-Jun;30(3):607-18. [Medline: 25671628] [doi: 10.11607/jomi.3886]

40. Del Fabbro M, Bortolin M, Taschieri S, Weinstein RL. Effect of autologous growth factors in maxillary sinus augmentation: a systematic review. Clin Implant Dent Relat Res. 2013 Apr;15(2):205-16. [Medline: 21453395] [doi: 10.1111/j.1708-8208.2011.00343.x]

41. Jensen T, Schou S, Gundersen HJ, Forman JL, Terheyden H, Holmstrup P. Bone-to-implant contact after maxillary sinus floor augmentation with Bio-Oss and autogenous bone in different ratios in mini pigs. Clin Oral Implants Res. 2013 Jun;24(6):635-44. [Medline: 22530746] [doi: 10.1111/j.1600-0501.2012.02438.x]

42. Schwartz-Arad D, Herzberg R, Dolev E. The prevalence of surgical complications of the sinus graft procedure and their impact on implant survival. J Periodontol. 2004 Apr;75(4):511-6. [Medline: 15152813] [doi: 10.1902/jop.2004.75.4.511]

43. Ardekian L, Oved-Peleg E, Mactei EE, Peled M. The clinical significance of sinus membrane perforation during augmentation of the maxillary sinus. J Oral Maxillofac Surg. 2006 Feb;64(2):277-82. [Medline: 16413901] [doi: 10.1016/j.joms.2005.10.031]

44. Lee HW, Lin WS, Morton D. A retrospective study of complications associated with 100 consecutive maxillary sinus augmentations via the lateral window approach. Int J Oral Maxillofac Implants. 2013 May-Jun;28(3):860-88. [Medline: 23748320] [doi: 10.11607/jomi.2793]

45. Geminiani A, Tsigarida A, Chochlidakis K, Papaspyridakos PV, Feng C, Ercoli C. A meta-analysis of complications during sinus augmentation procedure. Quintessence Int. 2017;48:231-40. [Medline: 28168239]

46. Schwarz L, Schiebel V, Hof M, Ulm C, Watzek G, Pommer B. Risk Factors of Membrane Perforation and Postoperative Complications in Sinus Floor Elevation Surgery: Review of 407 Augmentation Procedures. J Oral Maxillofac Surg. 2015 Jul;73(7):1275-82. [Medline: 25921824] [doi: 10.1016/j.joms.2015.01.039]

47. Ghasemi S, Fotouhi A, Moslemi N, Chinipardaz Z, Kolahi J, Paknejad M. Intra- and Postoperative Complications of Lateral Maxillary Sinus Augmentation in Smokers vs Nonsmokers: A Systematic Review and Meta-Analysis. Int J Oral Maxillofac Implants. 2017 July/August;32(4):759-67. [Medline: 28334056] [doi: 10.11607/jomi.5364]

48. Lundgren S, Andersson S, Gualini F, Sennerby L. Bone reformation with sinus membrane elevation: a new surgical technique for maxillary sinus floor augmentation. Clin Implant Dent Relat Res. 2004;6(3):165-73. [Medline: 15726851] [doi: 10.1111/j.1708-8208.2004.tb00224.x]

49. Lin IC, Gonzalez AM, Chang HJ, Kao SY, Chen TW. A 5-year follow-up of 80 implants in 44 patients placed immediately after the lateral trap-door window procedure to accomplish maxillary sinus elevation without bone grafting. Int J Oral Maxillofac Implants. 2011 Sep-Oct;26(5):1079-86. [Medline: 22010092]

50. Cricchio G, Sennerby L, Lundgren S. Sinus bone formation and implant survival after sinus membrane elevation and implant placement: a 1- to 6-year follow-up study. Clin Oral Implants Res. 2011 Oct;22(10):1200-12. [Medline: 21906186] [doi: 10.1111/j.1600-0501.2010.02096.x

51. Borges FL, Dias RO, Piattelli A, Onuma T, Gouveia Cardoso LA, Salomão M, Scarano A, Ayub E, Shibli JA. Simultaneous sinus membrane elevation and dental implant placement without bone graft: a 6-month follow-up study. J Periodontol. 2011 Mar;82(3):403-12. [Medline: 21054229] [doi: 10.1902/jop.2010.100343]

52. Altintas NY, Senel FC, Kayipmaz S, Taskesen F, Pampu AA. Comparative radiologic analyses of newly formed bone after maxillary sinus augmentation with and without bone grafting. J Oral Maxillofac Surg. 2013 Sep;71(9):1520-30. [Medline: 23866779] [doi: 10.1016/j.joms.2013.04.036]

53. Thor A, Sennerby L, Hirsch JM, Rasmusson L. Bone formation at the maxillary sinus floor following simultaneous elevation of the mucosal lining and implant installation without graft material: an evaluation of 20 patients treated with 44 Astra Tech implants. J Oral Maxillofac Surg. 2007 Jul;65(7 Suppl 1):64-72. Erratum in: J Oral Maxillofac Surg. 2008 Oct;66(10):2195-6. [Medline: 17586351] [doi: 10.1016/j.joms.2006.10.047]

54. Sohn DS, Lee JS, Ahn MR, Shin HI. New bone formation in the maxillary sinus without bone grafts. Implant Dent. 2008 Sep;17(3):321-31. [Medline: 18784532] [doi: 10.1097/ID.0b013e318182f01b]

55. Moon JW, Sohn DS, Heo JU, Shin HI, Jung JK. New bone formation in the maxillary sinus using peripheral venous blood alone. J Oral Maxillofac Surg. 2011 Sep;69(9):2357-67. [Medline: 21719179] [doi: 10.1016/i.joms.2011.02.092]

56. Falah M, Sohn DS, Srouji S. Graftless sinus augmentation with simultaneous dental implant placement: clinical results and biological perspectives. Int J Oral Maxillofac Surg. 2016 Sep;45(9):1147-53. [Medline: 27256011] [doi: $10.1016 /$ j.ijom.2016.05.006]

57. Summers RB. The osteotome technique: Part 3-Less invasive methods of elevating the sinus floor. Compendium. 1994 Jun;15(6):698, 700, 702-694 passim; quiz 710. [Medline: 7994726]

58. Pjetursson BE, Lang NP. Sinus floor elevation utilizing the transalveolar approach. Periodontol 2000. 2014 Oct;66(1): 59-71. [Medline: 25123761] [doi: 10.1111/prd.12043]

59. Pjetursson BE, Rast C, Brägger U, Schmidlin K, Zwahlen M, Lang NP. Maxillary sinus floor elevation using the (transalveolar) osteotome technique with or without grafting material. Part I: Implant survival and patients' perception. Clin Oral Implants Res. 2009 Jul;20(7):667-76. [Medline: 19486079] [doi: 10.1111/j.1600-0501.2009.01704.x] 
60. Shi JY, Gu YX, Zhuang LF, Lai HC. Survival of Implants Using the Osteotome Technique With or Without Grafting in the Posterior Maxilla: A Systematic Review. Int J Oral Maxillofac Implants. 2016 Sep-Oct;31(5):1077-88. [Medline: 27632263] [doi: 10.11607/jomi.4321]

61. Chen MH, Shi JY. Clinical and Radiological Outcomes of Implants in Osteotome Sinus Floor Elevation with and without Grafting: A Systematic Review and a Meta-Analysis. J Prosthodont. 2017 Jan 12. [Medline: 28084057] [doi: 10.1111/jopr.12576]

62. Pjetursson BE, Ignjatovic D, Matuliene G, Brägger U, Schmidlin K, Lang NP. Maxillary sinus floor elevation using the osteome technique with or without grafting material. Part II - Radiographic tissue remodeling. Clin Oral Implants Res. 2009 Jul:20(7):677-83. [Medline: 19515059] [doi: 10.1111/j.1600-0501.2009.01721.x]

63. Nedir R, Nurdin N, Vazquez L, Abi Najm S, Bischof M. Osteotome Sinus Floor Elevation without Grafting: A 10-Year Prospective Study. Clin Implant Dent Relat Res. 2016 Jun;18(3):609-17. [Medline: 25786548] [doi: 10.1111/cid.12331]

64. Tan WC, Lang NP, Zwahlen M, Pjetursson BE. A systematic review of the success of sinus floor elevation and survival of implants inserted in combination with sinus floor elevation. Part II: transalveolar technique. J Clin Periodontol. 2008 Sep:35(8 Suppl): 241-54. [Medline: 18724853] [doi: 10.1111/j.1600-051X.2008.01273.x]

\author{
To cite this article: \\ Starch-Jensen T, Jensen JD. \\ Maxillary Sinus Floor Augmentation: a Review of Selected Treatment Modalities \\ J Oral Maxillofac Res 2017;8(3):e3 \\ URL: http://www.ejomr.org/JOMR/archives/2017/3/e3/v8n3e3.pdf \\ doi: $10.5037 /$ jomr.2017.8303
}

Copyright (C) Starch-Jensen T, Jensen JD. Published in the JOURNAL OF ORAL \& MAXILLOFACIAL RESEARCH (http://www.ejomr.org), 30 September 2017.

This is an open-access article, first published in the JOURNAL OF ORAL \& MAXILLOFACIAL RESEARCH, distributed under the terms of the Creative Commons Attribution-Noncommercial-No Derivative Works 3.0 Unported License, which permits unrestricted non-commercial use, distribution, and reproduction in any medium, provided the original work and is properly cited. The copyright, license information and link to the original publication on (http://www.ejomr.org) must be included. 